\title{
Emergency physicians' management of transient ischemic attack and desired sensitivity of a clinical decision rule for stroke in three countries
}

\author{
Jeffrey J. Perry, MD, MSc ${ }^{*}$; Reena Goindi, MD*; Jamie Brehaut, PhD*; Monica Taljaard, PhD*; \\ Sandra Schneider, $\mathrm{MD}^{\dagger}$; Ian G. Stiell, MD, MSc
}

\section{ABSTRACT}

Objective: Four to $10 \%$ of patients with transient ischemic attack (TIA) suffer a stroke or die within 7 days. Our objectives were to determine (1) current practice for investigating and treating emergency department (ED) patients with TIA, (2) willingness to use a clinical decision rule to identify patients at high risk of impending stroke or death, and (3) the required sensitivity of this rule.

Methods: We administered a mail survey to a random sample of members of three national emergency physician associations in Australia, Canada, and the United States using a modified Dillman technique. A prenotification letter and up to three surveys were sent.

Results: A total of 801 responses (53.7\%) from 1,493 surveys were received; $53.6 \%(95 \% \mathrm{Cl} 47.5-59.7)$ of emergency physicians reported routinely admitting TIA patients, ranging from $6.6 \%$ in Canada to $56.7 \%$ in the United States, and $9.9 \%$ of emergency physicians have a stroke prevention clinic, with $4.7 \%$ estimating that patients are seen within 7 days. A sensitive clinical decision rule for TIA patients would be used by $96.3 \%$ (95\% Cl 93.9-98.7) of emergency physicians. The median required sensitivity of this rule for stroke or death within 7 days was $97 \%$.

Conclusions: Almost half of all TIA patients are managed as outpatients, which is neither expedited nor in a dedicated stroke clinic. Emergency physicians indicate a willingness to use a highly sensitive clinical decision rule to triage TIA patients.

\section{RÉSUMÉ}

Objectifs: De 4 à $10 \%$ des patients victimes d'un accident ischémique transitoire (AIT) ont un accident vasculaire cérébral (AVC) ou meurent dans les 7 jours suivant I'AIT. Nos objectifs étaient de déterminer 1) la pratique actuelle en matière d'examens et de prise en charge de patients se présentant à l'urgence avec des symptômes d'un AIT; 2) le désir $d^{\prime} u t i l i s e r$ une règle de décision clinique pour repérer les patients à haut risque d'AVC ou de mort imminente; 3) la sensibilité requise de cette règle.

Méthode: Nous avons réalisé un sondage par voie postale auprès d'un échantillon aléatoire de membres de trois associations nationales de médecins d'urgence en Australie, au Canada et aux États-Unis et avons utilisé une version modifiée de la méthode Dillman. Nous avons envoyé aux participants une lettre de pré-avis et jusqu'à trois questionnaires.

Résultats: Nous avons reçu 801 réponses (53,7\%) sur 1493 questionnaires envoyés. Quelque 53,6 \% (intervalle de confiance [IC] à $95 \%$, de 47,5 à $59,7 \%$ ) des médecins d'urgence ont dit admettre couramment à l'hôpital les patients victimes d'un AIT, allant de 6,6\% au Canada à 56,7 $\%$ aux États-Unis. Par ailleurs, 9,9 \% des médecins d'urgence ont accès à une clinique de prévention des AVC et $4,7 \%$ estiment que les patients y sont admis dans les 7 jours qui suivent. Une règle de décision clinique sensible serait utilisée pour les patients victimes d'un AIT par 96,3\% (IC à $95 \%$, de $93,9$ à $98,7 \%)$ des médecins d'urgence. La sensibilité médiane requise pour cette règle prédictive d'AVC ou de décès dans les 7 jours était de $97 \%$.

Conclusion: Près de la moitié de tous les patients victimes d'un AIT sont pris en charge en clinique externe, et cette prise en charge n'est ni précipitée ni réalisée dans une clinique de prévention des AVC. Les médecins d'urgence ont indiqué une volonté $d^{\prime} u t i l i s e r$ une règle de décision clinique hautement sensible pour le triage des patients victimes d'un AIT.

Keywords: clinical decision rules, transient ischemic attack (TIA)

From the *Department of Emergency Medicine, Department of Epidemiology and Community Medicine, Clinical Epidemiology Program, Ottawa Hospital Research Institute, University of Ottawa, Ottawa, ON; and tDepartment of Emergency Medicine, University of Rochester, Rochester, NY.

Presented at Canadian Association of Emergency Physicians, Ottawa, ON, June 2008.

Correspondence to: Dr. Jeffrey J. Perry, Clinical Epidemiology Unit, F6, Ottawa Hospital Research Institute, The Ottawa Hospital, Civic Campus, 1053 Carling Avenue, Ottawa, ON K1Y 4E9; jperry@ohri.ca.

This article has been peer reviewed. 


\section{INTRODUCTION}

\section{Background}

There are approximately 297,000 annual emergency department (ED) visits in the United States for transient ischemic attack (TIA). ${ }^{1}$ TIA is defined as a sudden, focal neurologic deficit lasting for less than 24 hours, presumed to be of vascular origin, and confined to an area of the brain or eye perfused by a specific artery. ${ }^{2,3}$ Although often considered benign, the diagnosis of TIA carries an important risk of stroke or death shortly after diagnosis. The risk of stroke is 4 to $10 \%$ within the first 7 days following a TIA and increases to 8 to $12 \%$ by 90 days. ${ }^{4-9}$ Stroke is a major public health concern in the United States, with more than 750,000 new strokes occurring each year, making stroke the leading cause of adult disability and the third leading cause of death in North America. ${ }^{10,11}$ Given the high incidence of TIA, it would be very resource intensive to fully investigate and obtain immediate specialist consultation for all ED patients with this condition. However, it is critical to identify high-risk TIA patients to ensure that all possible preventive measures are employed to decrease the probability of subsequent stroke. ${ }^{12,13}$ Currently, there are three published studies in which researchers have attempted to develop a clinical decision rule for high-risk TIA patients. ${ }^{9} 14,15$ None of these have followed the accepted methodology for developing a clinical decision rule. Two used retrospective data analysis, whereas the third was a small cohort study with delayed outpatient assessment by a neurologist. We are not aware of any research to determine the required accuracy of emergency physicians of such clinical decision rules for stroke following TIA.

\section{Importance}

We felt that a survey was required to determine how sensitive a clinical decision rule for stroke detection would need to be. Beyond the limitations of the current rules, the best rule to date, the $\mathrm{ABCD}^{2}$ rule, is only $83 \%$ sensitive when using its high-risk criteria for stroke or death within 1 week. ${ }^{14}$ Given this relatively low sensitivity, it is important to determine if physicians are following these rules. In addition, admission rates have been previously reported to vary from up to $54 \%$ in the United States to $24 \%$ in Canada. ${ }^{1,5}$ Therefore, it is important to determine how
TIA patients are currently managed in different countries with similar standards of living.

\section{Objectives}

The objective of this study was to determine, in a sample of emergency physicians from three countries, (1) current practices for investigating and treating ED patients with TIA, (2) the willingness of emergency physicians to use a clinical decision rule to identify patients at high risk of impending stroke or death, and (3) the required sensitivity of a clinical decision rule for TIA patients for subsequent stroke within 7 days.

\section{METHODS}

\section{Study design and setting}

We conducted a prospective, self-administered mail survey of members of three national emergency physician associations in Australia, Canada, and the United States. We used a modified Dillman tailored design method. ${ }^{16}$ The study was conducted between May and October 2007 and was approved by the research ethics board of the Ottawa Hospital.

\section{Selection of participants}

A total of 1,500 members of three national emergency physician associations were randomly selected for enrolment: 500 members of the Australasian College of Emergency Medicine (total membership 722), 500 members of the Canadian Association of Emergency Physicians (CAEP; total membership 1,675), and 500 members of the American College of Emergency Physicians (ACEP; total membership 23,000). Random selection was completed by each physician association using computer-generated random numbers. The sample size of 500 per organization was chosen to yield a desired precision of approximately \pm $4 \%$ around estimates of proportions in each country, based on the most conservative proportion of $50 \%$. Respondents not practicing adult emergency medicine were excluded from the analysis.

\section{Survey content}

The survey was three pages in length and primarily consisted of closed-ended questions. One page pertained 
to TIA, one page demographics, and one additional page assessed attitudes toward clinical decision rules for acute respiratory conditions (communityacquired pneumonia, congestive heart failure, and chronic obstructive pulmonary disease). This article relates only to the results of the TIA portion of the survey. Participants were asked questions on their current practice for investigation and management of patients with TIA in the ED, whether they would consider using a clinical decision rule to identify those at high risk of an impending stroke or death, and the required sensitivity of such a rule. The survey was pilot-tested on 40 emergency physicians at the Ottawa Hospital and revised to incorporate the feedback received.

Participants were asked 13 questions on their current practices for ordering diagnostic tests and treatments and responded on a 5-point Likert-like scale (with choices of always, most of the time, some of the time, almost never, and never). We also asked physicians whether their facility had a dedicated stroke prevention/management clinic (given choices of yes, no, and don't know) and whether the median time to be seen in this clinic was less than 1 week (given choices of yes, no, and don't know).

Participants were asked (1) if they would consider using a highly sensitive and well-validated clinical decision rule in TIA patients in the ED (given choices of yes and no) and (2) how sensitive they would require this rule to be in identifying patients who suffer a complete stroke or die less than 7 days from their initial ED visit for a TIA (given choices of $<80 \%, 80$ to $84 \%$, and 85 to $89 \%$ and integers from 90 to $100 \%$ ). Participants also answered 10 questions relating to their professional status (eg, age, years in practice, and practice setting).

\section{Survey administration}

All potential subjects received a prenotification letter by post that described the study and requested their participation. One week later, participants were sent a cover letter describing the study, assuring confidentiality, and containing the survey instrument and instructions on its completion. Nonrespondents were sent a minimum of two reminder letters, each including the survey instrument, at 4-week intervals. The survey included a postage-paid, preaddressed reply envelope to facilitate responses. No incentives for participation were offered.

\section{Data collection and processing}

All data were entered into a Microsoft Excel electronic database. Single data entry was used. During the data entry process, a validity check was done on a random sample of $5 \%$ of surveys.

\section{Primary data analysis}

Our primary outcome measures were (1) the percentage of physicians who would consider using a clinical decision rule for patients with TIA to identify those at high risk of an impending stroke or death and (2) the required sensitivity of such a rule. Secondary outcomes related to current practice for the investigation and treatment of patients with TIA in the ED.

Data were analyzed using SPSS version 16 (SPSS Inc., Chicago, IL). Univariate descriptive statistics were used. Frequency distributions were generated for all closedended questions. Primary and secondary outcome measures were calculated by country and overall, taking into account the stratified sampling design; 95\% confidence intervals with finite population correction factors were calculated around each point estimate.

\section{RESULTS}

Of the 1,493 surveys sent, 801 emergency physicians responded, resulting in an aggregate response rate of $53.7 \%$. Country-specific response rates were Australia, $55.4 \%$ (277 of 500); Canada, $60.0 \%$ (296 of 493); and the United States, $45.6 \%$ (228 of 500). Seven surveys in Canada were returned because they were undeliverable.

Physician demographic and practice setting characteristics are provided by country in Table 1. Overall, $74.0 \%$ of respondents were male, with a mean age of 43.0 years and an average of 12.0 years of clinical experience, and $73.2 \%$ worked at a teaching hospital. Nearly all respondents had 24-hour on-site access to a computed tomographic (CT) scanner.

The results for the series of questions relating to emergency physicians' current diagnostic practices for TIA patients are shown in Figure 1. Overall, the estimated proportion of physicians who always or most often investigate TIA patients with head CT was 96.7\% (95\% CI 94.8-98.6), with country-specific CT rates ranging from a low of $86.8 \%$ in Canada to a high of $97.6 \%$ in the United States. The estimated 


\begin{tabular}{|c|c|c|c|c|}
\hline & Australia ( $n=277)$ & Canada $(n=296)$ & $\begin{array}{l}\text { United States } \\
\qquad(n=228)\end{array}$ & Overall $(N=801)$ \\
\hline Mean age, yr (range) & $42.3(32-63)$ & $42.3(27-66)$ & $44.6(31-77)$ & $43.0(27-77)$ \\
\hline Male, \% & 70.0 & 73.9 & 79.5 & 74.0 \\
\hline $\begin{array}{l}\text { Mean years of practice } \\
\text { (range) }\end{array}$ & $12.6(1-34)$ & $12.0(1-35)$ & $13.2(1-33)$ & $12.0(1-35)$ \\
\hline Teaching hospital, \% & 93.1 & 75.8 & 44.4 & 73.2 \\
\hline $\begin{array}{c}\text { Annual ED visits } \\
>50,000, \%\end{array}$ & 42.4 & 48.9 & 39.5 & 44 \\
\hline CT scan available 24 h, \% & 90.5 & 80.7 & 99.5 & 89.5 \\
\hline $\begin{array}{l}\text { CT scan available } \\
\text { working hours only, \% }\end{array}$ & 9.1 & 11.0 & 0.5 & 7.4 \\
\hline $\begin{array}{l}\text { Neurologist available } \\
24 \text { h, \% }\end{array}$ & 43.3 & 47.9 & 66.8 & 51.6 \\
\hline
\end{tabular}

proportion of emergency physicians who routinely order an electrocardiogram (ECG) was $94.3 \%$ (95\% CI 91.5-97.2), ranging from a low of $94.2 \%$ in the United States to a high of $97.0 \%$ in Australia. There were large differences between the use of carotid Doppler ultrasonography between countries. There was also a large difference in admission rates. Overall, $53.6 \%$ of physicians indicated that they admit their
TIA patients "always" or "most of the time" $(95 \%$ CI $47.5-59.7)$; however, this varied from a low of $6.6 \%$ in Canada to a high of $56.7 \%$ in the United States. The proportion of emergency physicians with a dedicated stroke prevention clinic to follow their patients was 9.9\% (ranging from a low of $5.8 \%$ in the United States to a high of $54.7 \%$ in Canada); however, only $4.7 \%$ (95\% CI 2.7-6.7) indicated that most patients are seen

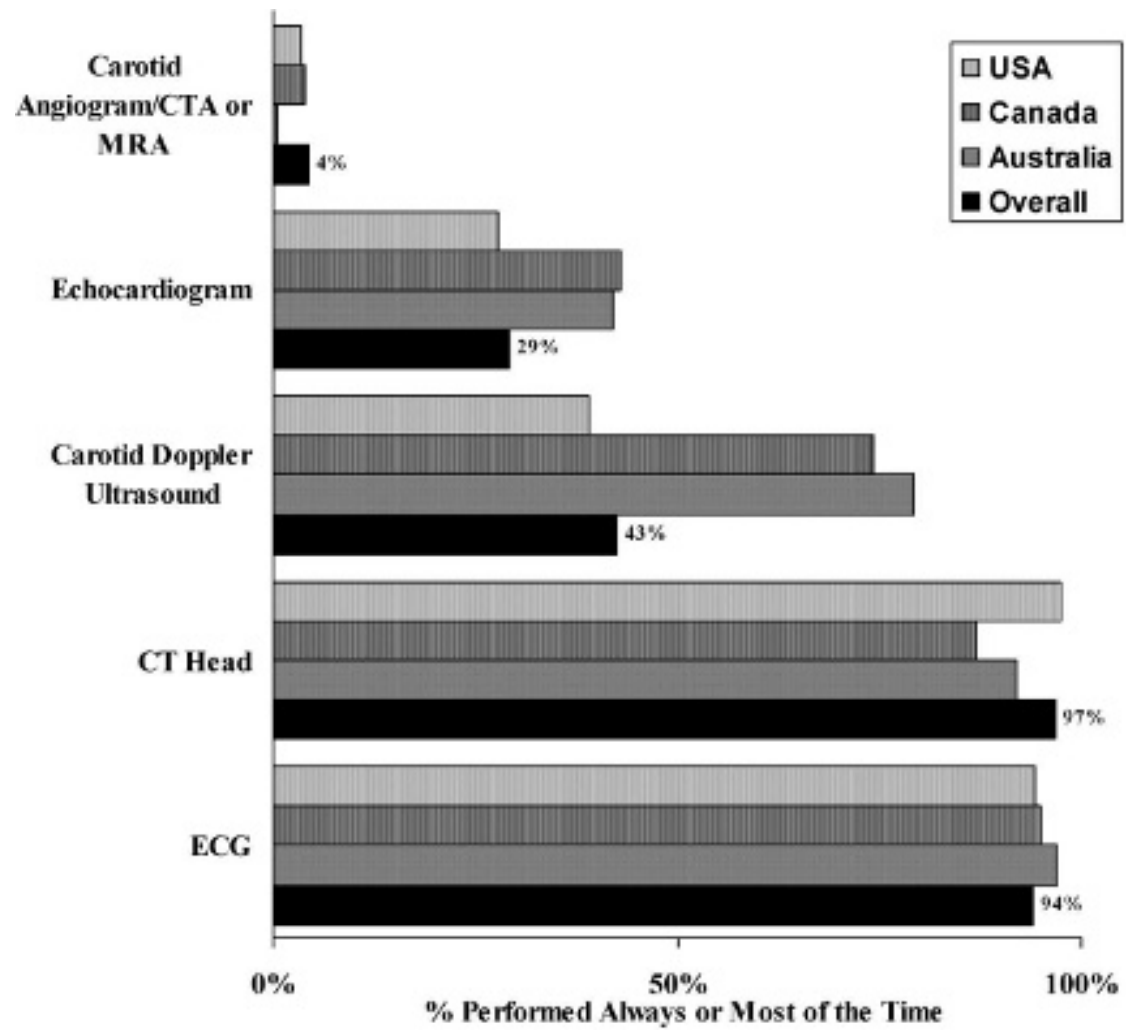

Figure 1. Overall and countryspecific current practice for investigation of transient ischemic attack in the emergency department. $\mathrm{CT}=$ computed tomography; $\mathrm{CTA}=$ computed tomographic angiogram; ECG = electrocardiogram; MRA = magnetic resonance angiogram. 
within 7 days of referral (ranging from a low of $2.5 \%$ in the United States to a high of $31.3 \%$ in Canada).

The results for the series of questions relating to their current treatment practices of TIA patients are shown in Figure 2. Overall, 88.5\% (95\% CI 84.5-92.5) of emergency physicians indicated that they treat patients with acetylsalicylic acid (ASA) "always" or "most of the time" (range 88.3-90.9\%). However, there was considerable variation in whether patients were treated with clopidogrel, with $8.3 \%$ overall responding "always" or "most of the time," ranging from a low of $3.1 \%$ in Australia to a high of $15.4 \%$ in Canada. For the combination of dipyridamole and ASA, the overall response was $10.5 \%$ (95\% CI $6.7-$ 14.3) answering "always" or "most of the time" to using this treatment, varying from a low of $9.6 \%$ in Canada to a high of $16.5 \%$ in Australia. Starting patients on or altering antihypertensive medication was also variable, with $41.7 \%$ (95\% CI 35.5-47.8) "always" or "most of the time" addressing this issue, ranging from a low of $11.0 \%$ in Australia to a high of $43.4 \%$ in the United States. Starting a statin medication was also variable, with $1.5 \%$ "always" or "most of the time" starting this treatment, ranging from a low of $1.0 \%$ in the United States to a high of $8.4 \%$ in Canada.

Our results indicated that clinical decision rules are currently variably used across the three study countries. The overall proportion of emergency physicians who either moderately or strongly agreed with the statement, "We already use a clinical decision rule to stratify TIA patients seen in our ED" was 11.2\% (95\% CI 7.3-15.0) (Australia, 30.8\%; Canada, 13.3\%; United States, 10.3\%). In contrast, 61.0\% (95\% CI 54.8-67.2) (Australia, 42.9\%; Canada, 54.5\%; United States, $62.0 \%$ ) of emergency physicians moderately or strongly disagreed with this statement, indicating that they do not use a TIA clinical decision rule in their practice.

Figure 3 indicates the required sensitivity of a clinical decision rule for the identification of patients at risk of a major stroke or death within 7 days of a TIA diagnosis. The overall median required sensitivity of this rule was $97 \%$ (98\% for both Canada and the United States and 97\% for Australia).

Figure 4 displays the willingness of physicians to consider using a well-validated clinical decision rule to guide the management of TIA patients seen in the ED. Overall, 96.3\% (95\% CI from 93.9-98.7) of emergency physicians indicated that they would use a highly sensitive rule to help identify high-risk TIA patients.

\section{DISCUSSION}

Our survey indicates that current practice for ED patients with TIA is varied across the three study

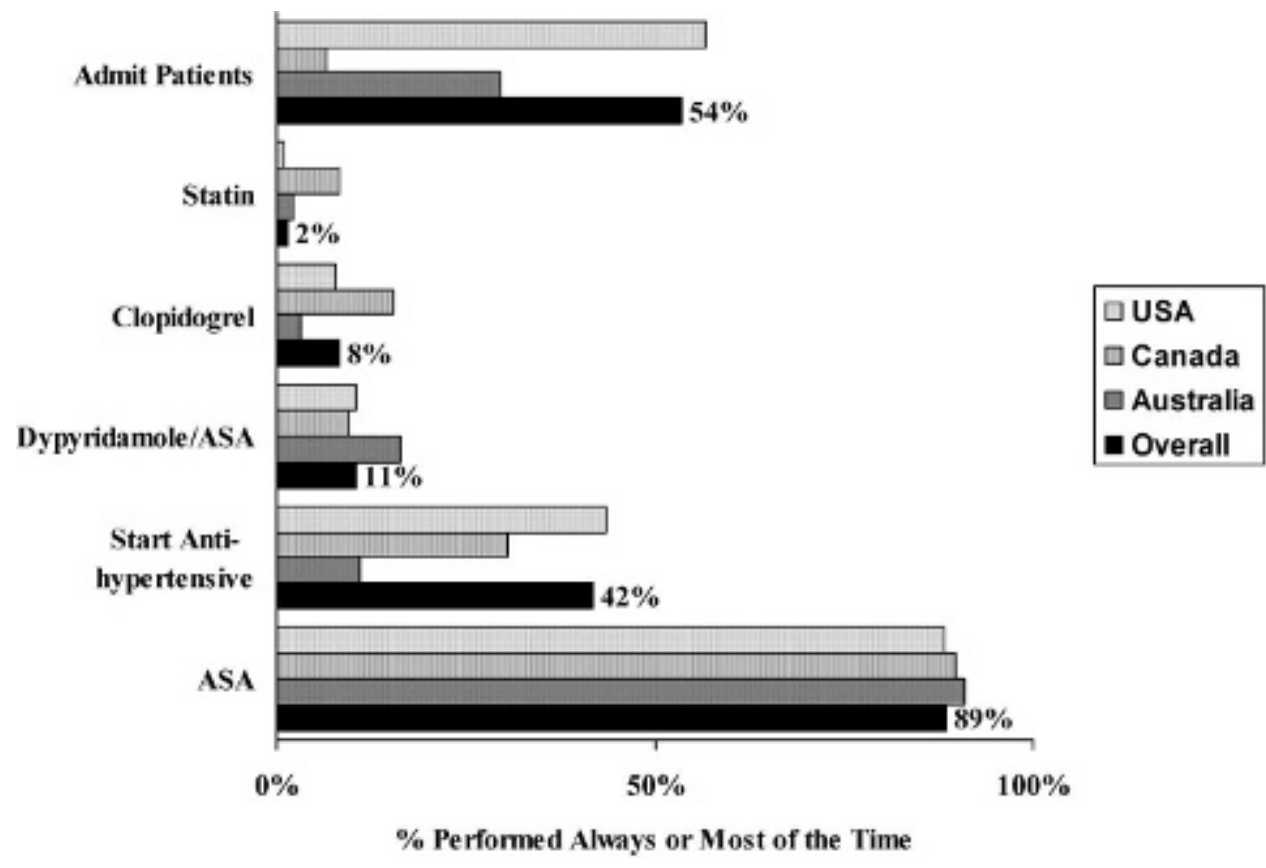

Figure 2. Overall and countryspecific current practice for treatment of transient ischemic attack in the emergency department. ASA $=$ acetylsalicylic acid. 


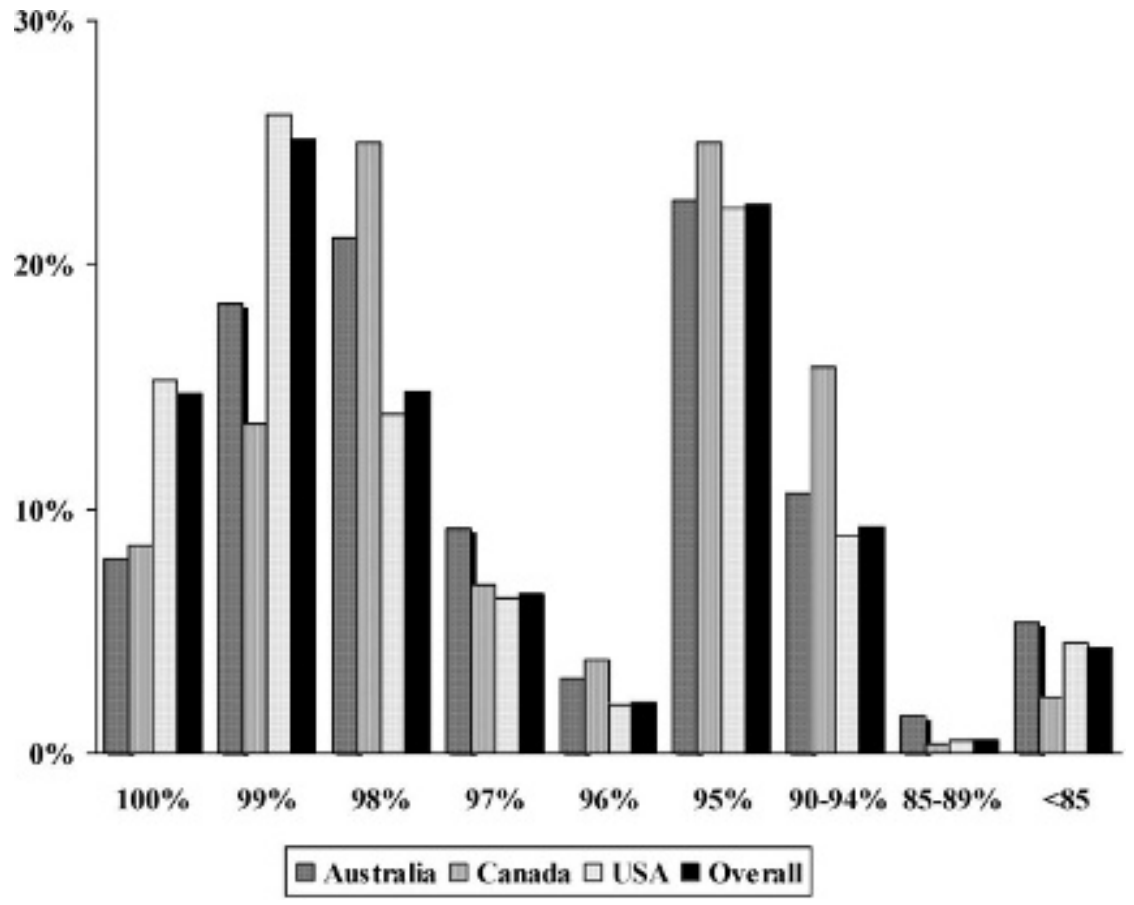

Figure 3. Required sensitivity for transient ischemic attack clinical decision rule categorized by country.

countries and that emergency physicians would consider using a clinical decision rule to identify patients at high risk of an impending stroke or death within 7 days of their TIA. The median required sensitivity of this rule was $97 \%$, a level higher than currently described clinical decision rules for TIA. CT head and ECG are routinely ordered by most emergency physicians in all three countries to investigate patients with TIA.
Carotid Doppler and echocardiograms are ordered more frequently by emergency physicians in Australia and Canada than in the United States. In contrast, in the United States, many more patients are admitted to hospital and more attention is placed on blood pressure management. Other immediate pharmacologic management of TIA patients is mainly restricted to the administration of ASA across all three study countries.

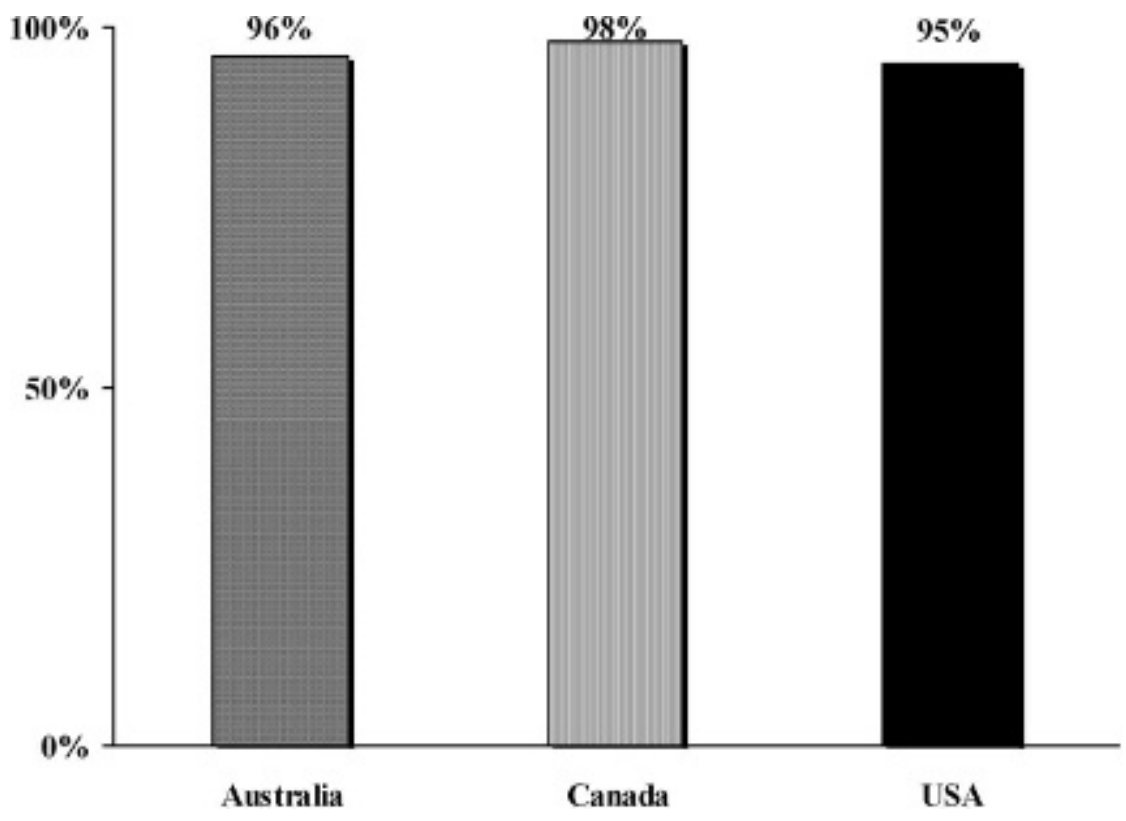

Figure 4. Willingness of emergency physicians to use a clinical decision rule for transient ischemic attack patients categorized by country. 
The admission rate reported by respondents in Canada is lower than that found in a previous database study. ${ }^{5}$ Although our study was not designed to directly address this difference, we did find that the Canadian sites had more accessibility to rapid outpatient management in dedicated stroke prevention clinics, which may account for this apparent difference. ${ }^{5}$ In contrast, our findings were similar to those of a previous study in the United States. ${ }^{1}$

Previous studies have attempted to identify high-risk TIA patients using clinical findings, and three rules with varying levels of sensitivity currently exist. Rothwell and colleagues derived the "ABCD rule" to assess for high risk of early stroke occurrence. ${ }^{15}$ Unfortunately, this rule has several limitations as the data set used was from 1981-1986 in the United Kingdom, a cohort that does not reflect current medical practice as secular changes have occurred in health care delivery models and treatment options. In addition, patients in the study were referred from physicians' offices and may have had less acute presentations than patients generally seen in EDs. Finally, patients in this study were assessed by neurologists and not emergency physicians. All of the aforementioned factors decrease the generalizability of this rule. Two recent studies further assessed the ABCD rule and found sensitivities for predicting stroke within 7 days of a TIA of only $72 \%$ (95\% CI 66-77) and 75\% (95\% CI 66-82). ${ }^{17,18}$ These sensitivities are too low to be clinically acceptable to emergency physicians.

Johnston and colleagues developed another clinical prediction rule from retrospective data analysis. ${ }^{9}$ This rule also has limitations as it was conducted solely in the San Francisco Bay area, which limits its generalizability. The authors used a chart extraction method; hence, the study is limited by the biases of retrospective data analysis. In addition, neither the reliability nor the sensitivity of the rule was assessed.

Johnston and colleagues subsequently merged their two data sets, which comprised their respective previous rules, in an attempt to derive and validate a new rule called the $\mathrm{ABCD}^{2}$ rule. ${ }^{14}$ Unfortunately, this study also has the same limitations as the original studies. Using the data from the validation cohort and an $\mathrm{ABCD}^{2}$ score of 6 to 7 as high risk, the sensitivity of the $\mathrm{ABCD}^{2}$ rule for predicting stroke or death within 7 days of TIA was $83 \%$ (95\% CI 81-84), which, according to our results, remains insufficient for many emergency physicians. This may be a factor in our finding that only $11 \%$ of respondents currently use a clinical decision rule for TIA patients.

Our survey suggests that further efforts are required to develop a clinical decision rule for TIA that is more sensitive than those currently in existence. A reliable and well-validated rule with high sensitivity should improve the efficiency of patient care and decrease adverse outcomes and could conceivably be used by a wide range of medical specialists. Given the discrepancies in admission rates for TIA across the countries studied, further research should determine if outcomes are similar in Canada and the United States as there may be more cost-effective ways to prevent subsequent stroke in TIA patients.

\section{LIMITATIONS}

Our target population was emergency physicians as clinical decision rules are often used by these front-line caregivers. We chose to sample members of three national emergency medicine associations. We chose these three associations because in the case of Canada and Australia, they are the only emergency physician associations, and in the case of the United States, the ACEP is the largest emergency physician association. We do not have data on the total number of emergency physicians working in each study country or the demographics of these physicians. In Canada, the Canadian Medical Association Web site of physicians and specialties provides age and sex statistics for fulltime, specialty-trained emergency physicians; however, it does not include family physicians who work parttime in EDs. As emergency physicians who belong to these organizations are likely to be more academically inclined, the possibility of coverage error exists (ie, some physicians in the target population may not have had a chance to answer the survey). However, our finding that Canadian respondents had a mean age of 42.3 and $73.9 \%$ were male closely compares to the median age range of 45 to 54 and $81 \%$ male gender reported in the statistics for emergency physicians by the Canadian Medical Association in 2007.

Our response rate was relatively low, and we cannot exclude the possibility of nonresponse bias. We were unable to explore differences between respondents and nonrespondents because the associations would not provide us with nonrespondents' demographic information to protect their privacy and confidentiality. However, we obtained data about the association 
membership as a whole for Canada and the United States. In Canada, in 2009, there were 1,317 CAEP members: $58 \%$ worked full-time in the ED, $63.2 \%$ worked in urban teaching hospitals, and $19.4 \%$ worked in rural teaching centres. These statistics compare favourably to our survey response sample, where $78.5 \%$ indicated that they work in a teaching hospital. In the United States, the ACEP has 25,617 members. They have a mean age of 42.8 years, with $74.6 \%$ male gender and $57 \%$ working in urban centres. This corresponds well with our sample results of 44.6 years, $79.5 \%$ male gender, and $44.4 \%$ working in teaching centres. Although our overall response rate was less than the $80 \%$ considered ideal, our samples appear to be representative of their respective target populations. Moreover, our response rate is consistent with that of previous physician studies that have yielded a mean response rate of 52 to $54 \% .^{19,20}$

We surveyed countries that are predominantly English speaking as most clinical decision rules have been developed in English and their use would be most familiar to an English-speaking audience. Hence, the results of this survey cannot necessarily be extrapolated to other geographic or cultural areas. The United Kingdom was approached to participate; however, their emergency physician association would not provide us with a list of members or distribute surveys on our behalf, citing privacy concerns. Finally, because the study involved a survey instrument, most of the questions were closed ended and did not allow participants to expand or elaborate on their responses.

\section{CONCLUSION}

The majority of emergency physicians in Australia, Canada, and the United States would consider using a clinical decision rule to assist with investigation and management of TIA in the ED. Emergency physicians in all three countries indicated that such a clinical decision rule would need to be highly sensitive and well validated in identifying those patients who will likely suffer a stroke or die in less than 7 days from their ED visit.

A more sensitive TIA clinical decision rule than is currently available should help standardize emergent testing and management of high-risk TIA patients, thus improving patient care and potentially lowering health care costs. By stratifying patients into risk groups, health care resources could be allocated most appropriately. The results of this study indicate that the current $\mathrm{ABCD}^{2}$ rule to identify high-risk patients does not meet sensitivity requirements for the majority of emergency physicians and suggest that further efforts are warranted to develop a more sensitive clinical decision rule to identify high-risk TIA patients.

Competing interests: None declared.

\section{REFERENCES}

1. Edlow JA, Kim S, Pelletier AJ, et al. National study on emergency department visits for transient ischemic attack, 1992-2001. Acad Emerg Med 2006;13:666-72.

2. WHO MONICA Project Principal Investigators. The World Health Organization MONICA Project (monitoring trends and determinants in cardiovascular disease): a major international collaboration. 7 Clin Epidemiol 1988; 41:105-14.

3. Albers GW, Caplan LR, Easton JD, et al. Transient ischemic attack-proposal for a new definition. $N$ Engl 7 Med 2002;347:1713-6.

4. Hill MD, Yiannakoulias N, Jeerakathil T, et al. The high risk of stroke immediately after transient ischemic attack. Neurology 2004;62:2015-20.

5. Gladstone DJ, Kapral MK, Fang J, et al. Management and outcomes of transient ischemic attacks in Ontario. Can Med Assoc 7 2004;170:1099-104.

6. Lovett JK, Dennis MS, Sandercock PAG, et al. Very early risk of stroke after a first transient ischemic attack. Stroke 2003;34:e138-42.

7. Kleindorfer D, Panagos P, Pancioli A, et al. Incidence and short-term prognosis of transient ischemic attack in a population-based study. Stroke 2005;36:720-4.

8. Johnston SC. Transient ischemic attacks are emergencies. Stroke 2005;36:724.

9. Johnston SC, Gress DR, Browner WS, et al. Short-term prognosis after emergency department diagnosis of TIA. FAMA 2000;284:2901-6.

10. Carandang R, Seshadri S, Beiser A, et al. Trends in incidence, lifetime risk, severity and 30 day mortality of stroke over the past 50 years. $7 A M A$ 2009;296:2939-46.

11. Johnston SC. Transient ischemic attack. N Engl 7 Med 2002; 347:1687-92.

12. Rothwell PM, Giles MF, Chandratheva A, et al. Effect of urgent treatment of transient ischaemic attack and minor stroke on early recurrent stroke (EXPRESS study): a prospective population-based sequential comparison. Lancet 2007;370:1432-42.

13. Lavallee PC, Meseguer E, Abboud H, et al. A transient ischaemic attack clinic with round-the-clock access (SOSTIA): feasibility and effects. Lancet 2007;6:953-60.

14. Johnston SC, Rothwell PM, Nguyen-Huynh MN, et al. Validation and refinement of scores to predict very early 
stroke risk after transient ischaemic attack. Lancet 2007;369: 283-92.

15. Rothwell PM, Giles MF, Flossmann E, et al. A simple score (ABCD) to identify individuals at high early risk of stroke after transient ischaemic attack. Lancet 2005;366:29-36.

16. Dillman D. Mail and Internet surveys: the tailored design method. New York: Wiley; 2000.

17. Cucchiara BL, Messe SR, Taylor RA, et al. Is the ABCD score useful for risk stratification of patients with acute transient ischemic attack? Stroke 2006;37:1710-4.
18. Tsivgoulis G, Spengos K, Manta P, et al. Validation of the ABCD score in identifying individuals at high early risk of stroke after a transient ischemic attack: a hospital-based case series study. Stroke 2006;37:2892-7.

19. Cummings SM, Savitz LA, Konrad TR. Reported response rates to mailed physician questionnaires. Health Serv Res 2001;35:1347-55.

20. Asch D, Jedrziewski K, Christakis N. Response rates to mail surveys published in medical journals. 7 Clin Epidemiol 1997; 10:1129-36. 